\title{
References
}

Glénet SN, De Bisschop C, Vargas F, et al. Deciphering the nitric oxide to carbon monoxide lung transfer ratio: physiological implications. J Physiol 2007; 582: 767-775.

Hughes JM, van der Lee I. The TL,NO/TL,CO ratio in pulmonary function test interpretation. Eur Respir J2013; 41: 453-461. Guenard H, Varene N, Vaida P. Determination of lung capillary blood volume and membrane diffusing capacity in man by the measurements of NO and CO transfer. Respir Physiol 1987; 70: 113-120.

4 Roughton FJ, Forster RE. Relative importance of diffusion and chemical reaction rates in determining rate of exchange of gases in the human lung, with special reference to true diffusing capacity of pulmonary membrane and volume of blood in the lung capillaries. J Appl Physiol 1957; 11: 290-302.

5 Forster RE. Diffusion of gases across the alveolar membrane, In: Fishman AP, ed. Handbook of Physiology. Bethesda, American Physiological Society, 1987; pp. 71-88.

6 Borland CD, Dunningham H, Bottrill F, et al. Significant blood resistance to nitric oxide transfer in the lung. J Appl Physiol 2011; 108: 1052-1060.

7 Carlsen E, Comroe JH Jr. The rate of uptake of carbon monoxide and of nitric oxide by normal human erythrocytes and experimentally produced spherocytes. J Gen Physiol 1958; 42: 83-107.

8 Martinot JB, Mulè M, de Bisschop C, et al. Lung membrane conductance and capillary volume derived from the NO and CO transfer in high-altitude newcomers. J Appl Physiol (1985) 2013; 115: 157-166.

9 Aguilaniu B, Maitre J, Glénet S, et al. European reference equations for CO and NO lung transfer. Eur Respir J 2008; 31: 1091-1097.

10 Weibel ER, Federspiel WJ, Fryder-Doffey F, et al. Morphometric model for pulmonary diffusing capacity. I. Membrane diffusing capacity. Respir Physiol 1993; 93: 125-149.

\section{Doxycycline in lymphangioleiomyomatosis: not all questions are answered}

\author{
To the Editor:
}

We read with interest the article by CHANG et al. [1], which demonstrated doxycycline to have no effect on pulmonary function tests (PFTs) and is unlikely to have a potential benefit in lymphangioleiomyomatosis (LAM). An increase in metalloproteinases (MMPs) is considered one of the pathways involved in the pathogenesis of cystic lung destruction in LAM. As a result, doxycycline, a MMP inhibitor, may represent a potential therapeutic target [2-6].

One factor that could have determined a lack of effect on PFTs in the present study was that patients with LAM, treated with doxycycline, had moderate impairment in PFTs when compared with those receiving placebo, which had mild impairment. A recent nonrandomised study from our group has already suggested that patients who would most benefit with doxycycline are those with mild functional impairment [7]. Moreover, the small number of patients included may have limited the results in the present study.

From our previously published study [7], we re-evaluated the effect of the use of doxycycline (100 $\mathrm{mg} \cdot$ day $^{-1}$ ) in 24 patients for 3 years on PFTs. Baseline mean \pm sD forced expiratory volume in $1 \mathrm{~s}(\mathrm{FEV} 1)$ and diffusion capacity of the lungs for carbon monoxide (DLCO) were $2.30 \pm 0.67 \mathrm{~L}(81 \pm 21 \%$ pred) and $18 \pm 6.6 \mathrm{~mL} \cdot \mathrm{min}^{-1} \cdot \mathrm{mmHg}^{-1}(69 \pm 23 \%$ pred $)$, respectively. After 3 years, there was a significant reduction in FEV1 $(2.09 \pm 0.71 \mathrm{~L} ; \mathrm{p}<0.001)$ and in DLCO $\left(15.8 \pm 6.2 \mathrm{~mL} \cdot \mathrm{min}^{-1} \cdot \mathrm{mmHg}^{-1} ; \mathrm{p}=0.04\right)$. Rate of decline in FEV 1 in 3 years was $-73 \mathrm{~mL} \cdot$ year $^{-1}$. The majority of patients $(n=20 ; 83 \%)$ showed a decrease in FEV1. From the 13 patients that had a stabilisation of or an increase in FEV1 after receiving doxycycline for 1 year, 11 patients continued follow-up and showed a reduction in FEV1 after three years (group stabilisation/ increase). From 18 patients that showed a reduction in FEV1 in the first year, 13 continued follow-up and demonstrated the same tendency after 3 years (group decrease), figure 1.

The annual rate of decline in FEV1 in the present study was slightly greater $(-90 \mathrm{~mL}$ in the placebo group and $-123 \mathrm{~mL}$ in the doxycycline group) compared with that observed in the re-evaluation performed by our group $(-73 \mathrm{~mL}$ in patients that received doxycycline) and with that identified in the study of TaveiraDaSilva and colleagues $(-75 \mathrm{~mL})[1,8]$. Can we assign a greater decline in $\mathrm{FEV}_{1}$ identified in the doxycycline group in the present study to a greater impairment in baseline pulmonary function? We believe that there is still no response to this question.

Although doxycycline reduces the levels of MMPs in patients with LAM, we also agree with the authors that based on these recent studies the potential mechanism of action of doxycycline in LAM may be independent of the blockade of MMPs $[1,2,6,7]$. 

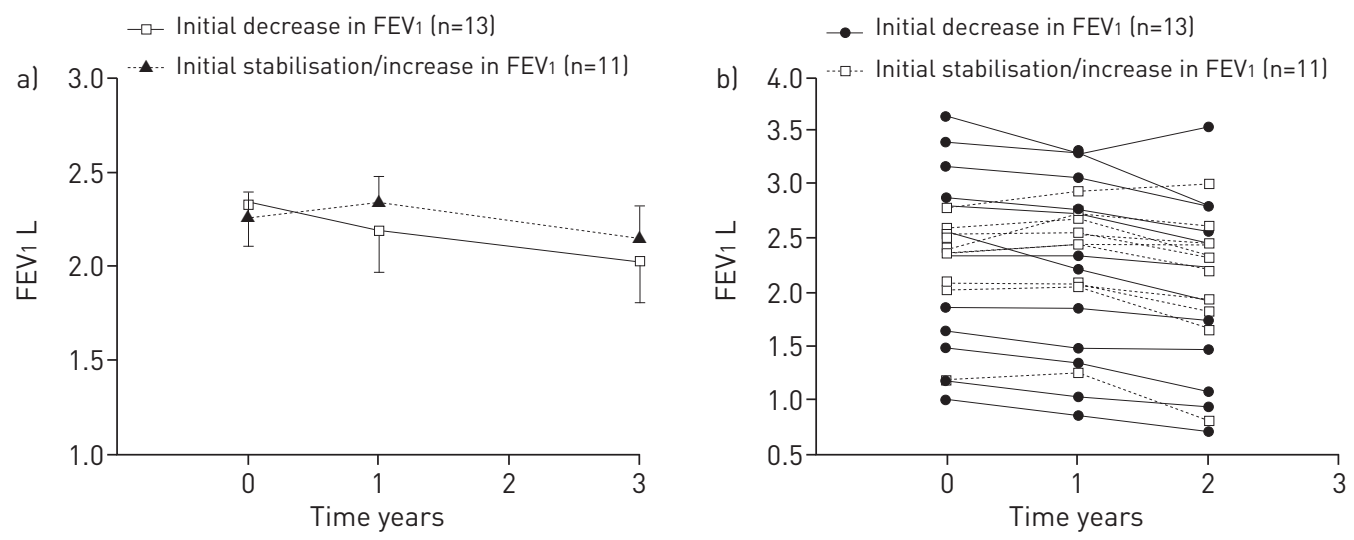

FIGURE 1 a) The mean forced expiratory volume in $1 \mathrm{~s}$ (FEV1) at baseline, 1 year and 3 years in the subgroup that initially had stabilisation/an increase in FEV1 and in the subgroup that initially had a decrease in FEV1. b) FEV1 at baseline, 1 year and 3 years in each patient of the subgroup that initially had stabilisation/an increase in FEV1 and in each patient of the subgroup that initially had decrease in FEV1.

Therefore, the present article [1] and our findings, after 3 years of treatment with doxycycline, suggest that the isolated use of this drug is not recommended for the long-term treatment in LAM. However, we believe that these results cannot exclude completely a potential benefit of this drug, mainly if it is used in combination with other medications, such as sirolimus [9] or even hormonal blockage [10], acting on different pathways involved in the pathogenesis of LAM, and in patients with mild functional impairment. In addition, although doxycycline is a safe drug, a limitation in evaluating the impact of this medication in LAM is that its optimal dosage has not yet been determined or in deed how long it should be taken for in order to achieve the proposed benefits.

○ @ERSpublications

Isolated use of doxycycline is not currently recommended: there are doubts whether this drug has any role in LAM http://ow.ly/tJWfU

Bruno Guedes Baldi and Carlos Roberto Ribeiro Carvalho

Pulmonary Division, Heart Institute (InCor), University of Sao Paulo Medical School, Sao Paulo, Brazil.

Correspondence: B.G. Baldi, Dr Enéas de Carvalho Aguiar Avenue, 44, Fifth floor, Postal Code 05403-900, Sao Paulo, Brazil. E-mail: bruno.guedes2@terra.com.br

Received: Jan 092014 | Accepted: Jan 202014

Conflict of interest: None declared

\section{References}

1 Chang WYC, Cane JL, Kumaran M, et al. A 2-year randomised placebo-controlled trial of doxycycline for lymphangioleiomyomatosis. Eur Respir J 2014; 43: 1114-1123.

2 Pimenta SP, Baldi BG, Acencio MM, et al. Doxycycline use in patients with lymphangioleiomyomatosis: safety and efficacy in metalloproteinase blockade. J Bras Pneumol 2011; 37: 424-430.

3 Matsui K, Takeda K, Yu ZX, et al. Role for activation of matrix metalloproteinases in the pathogenesis of pulmonary lymphangioleiomyomatosis. Arch Pathol Lab Med 2000; 124: 267-275.

4 Hayashi T, Fleming MV, Stetler-Stevenson WG, et al. Immunohistochemical study of matrix metalloproteinases (MMPs) and their tissue inhibitors (TIMPs) in pulmonary lymphangioleiomyomatosis (LAM). Hum Pathol 1997; 28: 1071-1078.

5 Odajima N, Betsuyaku T, Nasuhara Y, et al. Matrix metalloproteinases in blood from patients with LAM. Respir Med 2009; 103: 124-129.

6 Moses MA, Harper J, Folkman J. Doxycycline treatment for lymphangioleiomyomatosis with urinary monitoring for MMPs. N Engl J Med 2006; 354: 2621-2622.

7 Pimenta SP, Baldi BG, Kairalla RA, et al. Doxycycline use in patients with lymphangioleiomyomatosis: biomarkers and pulmonary function response. J Bras Pneumol 2013; 39: 5-15.

8 Taveira-DaSilva AM, Stylianou MP, Hedin CJ, et al. Decline in lung function in patients with lymphangioleiomyomatosis treated with or without progesterone. Chest 2004; 126: 1867-1874.

9 McCormack FX, Inoue Y, Moss J, et al. Efficacy and safety of sirolimus in lymphangioleiomyomatosis. N Engl J Med 2011; 364: 1595-1606.

10 Baldi BG, Medeiros Junior P, Pimenta SP, et al. Evolution of pulmonary function after treatment with goserelin in patients with lymphangioleiomyomatosis. J Bras Pneumol 2011; 37: 375-379. 